\title{
THE ETHICS OF EXCELLENCE IN TOURISM RESEARCH: A REFLEXIVE ANALYSIS AND IMPLICATIONS FOR EARLY CAREER RESEARCHERS
}

\author{
CATHERYN KHOO-LATTIMORE
}

Department of Tourism, Sport and Hotel Management, Griffith Business School, Queensland, Australia

\begin{abstract}
Set against the framework of today's competitive research environment, this article focuses on a less discussed category of ethics within tourism: that of the researcher as a professional. "Data" are presented as reflexive considerations on the ethical challenges and dilemmas an early career researcher faced during her transition from the early to mid-career phase. Personal experiences are compared to a multidisciplinary literature on ethics, education, knowledge production, and distribution. This article concludes that it is possible for early career researchers in the current tourism academic climate to remain ethical and successful at the same time-if they engage constantly and reflexively with the ethical questions that surround their own identity, power, and responsibility as academics. The article also asks that the tourism research community and institutional structures place more emphasis on the discussion of ethics and codes of conduct.
\end{abstract}

Keywords: Ethics; Reflexivity; Early career researcher; Female; Asian

Introduction

Discussions on research excellence and success within the tourism as a field of study have been recent and slowly gaining momentum (Fennell, 2013; Jamal, Smith, \& Watson, 2008; Jogaratnam, Chon, McCleary, Mena, \& Yoo, 2005; Law \& Chon, 2007; McKercher, 2005, 2008; McKercher, Law, \& Lam, 2006; Page, 2003; Pechlaner, Zehrer, Matzler, \& Abfalter, 2004). Many of these take the logical, economic approach and discuss success by ranking and rating the top tourism schools, journals, and even individual academics. This body of work suggests a benchmark and is particularly exemplary to early and mid-career researchers who are mapping out their career paths. However, at the same time there is growing evidence to suggest that early career researchers are becoming disillusioned and experiencing below-average success rates in academia (Hillen, Scholl, Martinelli, Gudzune, \& Pype, 2013; Laudel \& Gläser, 2008; National Research Council, 2005; Orlando \& Gard, 2014; Tilghman, 1998). Worrying reports about the transitions early career academics face are abound, 
varying in terms of perspectives and geography (Meyer, 2012; Petersen, Stanley, \& Succi, 2011; Schäfer et al., 2011). Yet, this phase of the career is crucial in ensuring the successful transformation of the academic from an "apprentice” into an independent researcher of caliber (Laudel \& Gläser, 2008).

Therefore, it is timely to be reflexive, as Hall (2004) advocated, on the various research communities and their beliefs for the measurement of success is a very core process that early career researchers are expected to partake in-that of knowledge production. In particular, some more discussions on the ethics by which academic success are built upon is needed. It is fortunate that within tourism, a few leading senior researchers have done so and subsequently proposed ideas for alternative measures of performance (Fennell, 2013; Hall, 2004; Ryan, 2005). Hall (2004) contemplated on how tourism research and the "games academics play" are influenced by the government and the academic society. He reinvigorated the need for academics to be reflexive and hence challenged tourism researchers to be so in their production of knowledge. Ryan (2005) was relatively optimistic about tourism research and outlined the backdrop for why academic performances need to be measured. Yet, he also questioned the representation of good, prominent scholars in the top-ranked journals. He was of the opinion that consideration for an academic's contribution should go beyond publications in top-ranked journals and h-indices. Instead, academics should be rewarded for their work in mentoring young and new researchers, publications in books, and other research leadership abilities. When a colleague he approached to write together with declined to do so on the basis that the article was targeted to a B-ranked journal, Fennel (2013) lashed out on the lack of ethics among tourism researchers. He was reflexive of current practices of tourism research and then almost concluded that there is minimal chance for ethics to flourish as long as excellence is measured quantitatively. Seemingly disenchanted, Fennel (2013) concluded, "As scholars, journals, and institutions retreat further into their own Darwinian worlds in the pursuit of academic excellence, there is the sense that we really have lost our way” (p. 424). Like Hall (2004) and Ryan (2005), Fennel (2013) also called for the tourism research community to be more accepting of and, consider aiming for, alternative measures of excellence. He cited the publications of books and the value of collegiality as examples. However, whether or not these suggestions for ethical "alternative excellence” can be or are adopted by early career researchers to succeed in current academic environments remains to be explored. In fact, Hall (2004) admitted that although it is virtuous to be reflexive, he is also aware that reflexivity and ideal behaviors following reflexivity might only be privileges accorded to those in established, secure, and senior positions such as himself. In addition, scholars writing on the subject of ethics and performance (not necessarily either or) have so far mainly focused on organizational and operational issues rather than what Trow (1976, cited in Becher \& Trowler, 2001) called the "private life” (p. 29) of academia. The latter is important because the questioning of the individual self in the big scheme of tourism research is the first step towards our understanding of the many selves who make up tourism research and our intellectual world. Reflexivity on the self is "where we should start, with ourselves, and ask some of those difficult questions" (Hall, 2004, p. 150).

Therefore, the focus of this article is on the individual "private life," that is, from the perspective of an early career researcher on ethically important moments during the process of knowledge production. The main objectives of this article are twofold: (a) to respond and comment on Fennel's (2013) plight for ethics and excellence to coexist; and (b) to be reflexive on a main question: is it possible, and more importantly feasible, for an early career researcher in the current tourism academic climate to remain ethical and successful at the same time? Success for the purpose of this article is defined as having exceeded the expectations of what needs to be achieved by an early career researcher (Bazeley et al., 1996) before the end of the early career "term," which is typically 5 to 6 years of being conferred the Ph.D. degree (Bazeley, 2003; Grbich, 1998; Laudel \& Gläser, 2008; Petersen, 2006; Schäfer et al., 2011). It is acknowledged that "current tourism academic climate" will vary according to geographical jurisdiction, but in this article the researcher has completed her research training in New Zealand, began her academic career in a university in Malaysia, spent 6 months 
in a research-intensive university in the US, and recently took up a new teaching and research position in Australia.

The rest of the article will be written in the first person, as I situate myself within my intellectual socialization context of tourism research. This context refers to the community of tourism researchers of which I have been, and am being socialized (Hall, 2004). This is the context that defines the culture of its faculty excellence. In this context, I am an Asian female researcher. I was conferred the doctoral degree in August 2009, and since then have had two children. The accorded maternity leave and my new role as mother have meant that my academic career was suspended twice, totaling a period that spans over 14 months. This means that since graduating with a Ph.D. in August 2009 until present day, I have been socialized in tourism research for an approximate period of 57 months. This, according to various academic definitions, places me in the early career phase, albeit at the finishing leg. As I approach the next career phase, a reflexive analysis of my transformation within the tourism research setting is opportune. The interpretive and reflexive nature of this work justifies autoethnography as a critical method. The foundation of autoethnography recognizes that individuals and culture are interwoven but that the individuals are cultural agents whose self-reflections are important platforms from which to observe the underlying social dynamism, power relations, and cultural influences that shape one's behaviors (Ellis, 2004; Noy, 2008). As such, autoethnography has been described as a technique that challenges the repressed voice (Dunkley, 2007) “without the pretense of detachment and often combines the deeply personal with the analytical” (Botterill \& Platenkamp, 2012, p. 17)—a technique most befitting the objectives of this article.

\section{The Ethics of Research: The Need to be Reflexive}

Discussions on ethics in research are not new and can be classified into three main categories. The first is procedural ethics, which "involves seeking approval from relevant ethics committee to undertake research involving humans," while the second is ethics in practice, referring to "everyday ethical issues that arise in the doing of research" (Guillemin \& Gillam, 2004, p. 263). The latter deals with the ethical dilemmas researchers face during data collection and questions how researchers should respond to certain circumstances that arise so as not to harm their participants (Brewer \& Hunter, 2006; Bulmer, 1982; Faden, Beauchamp, \& King, 1986) or themselves (Jamieson, 2000; LeeTreweek \& Linkogle, 2000; Liamputtong, 2006; Melrose, 2002; Mura, 2013). This article focuses on the third and a less-discussed category of ethics, which are the ethics typically set out in professional codes of conduct. Most professions and instructions have professional codes of conduct (Bulmer, 1982). This includes researchers, as evidenced by the research ethics documents put out by most if not all higher institutions, but Moscardo (2010) makes an interesting observation. She notes that unlike their counterparts in anthropology, sociology, or psychology, new cohorts of specialized tourism researchers do not seem to have been educated on any particular code of conduct, and so, have no guide on how to behave ethically during their research career. Paradoxically though, tourism researchers are concerned about the need for ethics for the industry (Donyadide, 2010; Fennell \& Malloy, 1999, 2007; Liamputtong, 2006; Malloy \& Fennell, 1998; Ong, Pearlman, Lockstone-Binney, \& King, 2013; Payne \& Dimanche, 1996; Weeden \& Boluk, 2014; Wheeler, 1995). Although it is important that tourism councils, destination planners, hospitality providers, planners, and legislators understand the ethics of their positions for the whole industry to continue to thrive in a sustainable manner, there is also a need for tourism academics to be reflexive of their own ethical attitudes in order to facilitate and progress tourism scholarship (Hall, 2011a; Macbeth, 2005). To do so, Moscardo (2010) raised four key questions, three of which will be the platform from which my reflexive analysis be based upon. Her fourth question- "Who and what is not studied and what does this mean for the welfare of those neglected?"-is beyond the focus of this article on excellence. In addition, although the answers to Moscardo's question is not exhaustive, it is in the interest of brevity that I have chosen to present in the following what I think are the most pressing concerns for an early career academic researcher. 
Why do we Study Some Aspects of Tourism but not Others?

Like Hall (2004), tourism research for me is an “accident” (p. 149). My Ph.D. from the School of Business at the University of Otago, New Zealand, was on consumer behavior in residential real estate. I had to be in Malaysia because my father's health was deteriorating. I accepted a position to work in a tourism and hospitality school. I had thought that I will be able to continue working on real estate issues within the tourism sector but discovered that I was not at all interested in the commercial issues of hotel and resort properties. At the same time, good colleagues included me in their projects and I took on an almost apprentice role. I began to familiarize myself with the tourism community and with it, the literature, the subdisciplines, and the who's who in tourism. Although I was an eager learner, my earlier publications were all "accidents” and most were not my choice of study areas. When I look back at my last 16 publications, I am amazed that except for four, all that I have cowritten on are not on topics that I have consciously and deliberately chosen to study. However, this is not to say that I was not interested in the topics (they all had some aspects of consumer behavior elements where I could contribute to) but the main reason why I studied them was, sadly to say, to move on in my career. I had already been on maternity leave for over a year, and I was starting out in a brand new field of study. I had no grant and no mentor. I had to be published and this was the way I knew how. However, as difficult as it is to declare so, it is far more frightening to understand that conducting research as a means to advance one's career has been so ingrained during the doctoral candidacy. This is cultivated in the message that one needs a Ph.D. to stay and advance in academia, and then that the Ph.D. is never enough without publications, that the h-index is crucial for promotion, that a successful researcher is the one that has published (Carson, Bartneck, \& Voges, 2013; Miller, Taylor, \& Bedeian, 2011; van Dalen \& Henkens, 2012). During the young researchers' formative years of training, debate on ethics of excellence may not have been given the same significance as the urgency to publish.

I am not proud of some of my publications but it is through these publications that I have immersed in and learned about tourism research and its community. Without these publications, I doubt if I would have been considered seriously by the different committees for promotion, grant approvals, speaking engagements, doctoral examinations, and the recent job application. Without these "successes" I would not have gained enough confidence to speak so convincingly during my lectures, and to venture into research topics that I really care about. The publications benefitted me on the personal level but also the community at large - the students, the school, the university, and perhaps even my country, Malaysia, and then my coauthors, their schools, their universities, and their countries. After all, Johnson (2011), in his guide for early career researchers where he also touched on ethics and research integrity, counsels:

Unless you have documentation of the acceptance of your research outputs by your peers, then you will be unable to prove to potential grant funders, promotion panels or new employers just how good your research output is, or indeed, even if you have been productive at all. (p. 44)

However, moving on and looking in the rear view mirror (Hall, 2004), I have now begun to develop what I believe is a full research agenda that will mark my "research trail' (Chubin \& Connolly, 1982). The agenda, which centers on women travelers and family tourism, concerns me as a traveler and tourist, but also as a woman and mother. These are topics that I can situate myself in and that I would have qualified as a participant. I am aware that although my studies seek to make a contribution to knowledge, there is much focus on improving the travel experience of people like me. The choice for my current research agenda is motivated by own ideals as much as the other factors stressed by Wenstøp and Koppang (2009)_factors such as my own experiences, circumstances, and curiosity. Although I have always strived to ensure that my data are trustworthy and unbiased, I can still be possibly criticized by positivists for not being entirely "objective" and therefore unethical, for their codes of ethical research conduct are centered on the notion of the researcher being independent of the researched and the research (Easterby-Smith \& Thorpe 1991; Hudson \& Ozanne, 1988; Perry, Riege, \& Brown, 1999). Perhaps the reasons why 
I studied certain aspects of tourism are not entirely altruistic but I am not sure if these reasons alone are deemed unethical. Publications on ethnography and autoethnography will suggest otherwise but except for Hall (2011a), these issues have never been deliberated by tourism researchers.

To answer the research question, my reflexive analysis thus far determines that it is exigent to say for sure if an early career researcher can succeed within 5 years of the early career period by being thoroughly ethical. First of all, the question of what is and is not ethical needs to be further debated. To this end, I agree with Moscardo (2010) that "the debate about such a code [of ethics specific to tourism research] could be useful in stimulating awareness of the issues” (p. 211).

\section{What Power do Tourism Researchers Have?}

Although power is relational to the context of who and where we are, tourism researchers as individual agencies have the power to address ethical issues. My personal dual identity is a case in point. I am an Asian with a Western last name with a Ph.D. from a Western university. This identity has a strong influence on my academic career. The scope and definition for academic success in Asia are different from those in the West, and therefore the tasks, roles, and responsibilities expected of an academic may also differ. When faced with administrative dilemmas during my 3 years in Malaysia, I have struggled to balance my Asian-Western values in determining who is right and who is wrong-I had blamed the Asians for all things negative and almost always assumed the Western way to be "more ethical.” Looking back and now forward, I recognize that the "Western" side of me had not attempted to understand why things are administered differently in Asia (Mayuzumi, 2008). For example, I have criticized Asian procedures as being rigid and inefficient, when I should have understood that these procedures have been reinforced by dominant Asian values such as face, respect, and honor for authorities (Zhang, 2011) that I no longer uphold as precedence in decision making. This realization of my own "cultural blindness" (Persson, 2012) is particularly significant given the many current instances of the Westernization of scientific endeavors and values in non-Western countries. The power to understand the "different others" from an AsianWestern perspective is insightful but the willingness to exercise this power to understand another is in itself an ethical act.

As an Asian, I also realize that the power associated to seniority and titles such as Drs. and Professors is more potent than I would have liked (Hook, 1984; Wright, 2009). The Asian values of filial piety and respect for knowledge that have been instilled in me as a young child have permeated into an obligation to obey stature. I can now appreciate how my current students (particularly if they are Asians) as apprentices in training may feel the pressure to accommodate research to the preferences of academics more seasoned and senior than them. Having to work outside one's own research area to complement the objectives of funding agencies may to a certain extent undermined one's freedom to think and act independently. I had been merely instructed to collect data, write the literature review, or put undeserving names on an article. I paid my dues, albeit begrudgingly, and today I acknowledge this power in my relationship with my own colleagues and especially graduate students. With excellence ethics in mind, this power connected to seniority and titles should be more carefully considered. For example, assignments could be less of a prescription and more of a mutual agreement. Tourism researchers working with Asian colleagues and students could be more sensitive so as not to take advantage, even if unintentionally, of the power that accompanies their titles.

The power associated to the prestige of having a Ph.D. abbreviated to one's name is not to be underestimated in research. The researcher's title might create for the research participants the view that the researcher is a professional authority. This will in turn influence the results of the study, be it a qualitative or quantitative one. The same is to be said with the way the researcher speaks and/or is dressed (i.e., more smartly than the participants) (Ballinger \& Payne, 2000). This finding implies that the discussion of power in professional ethical conduct should be included in texts on research design (such as those by Finn, Elliott-White, \& Walton, 2000; Fowler, 2014; Veal, 2006) and how response errors could have been caused by assumed researcher power during data collection (Darbi \& Hall, 2014). Ethics committees might include this concern when reviewing procedural ethics applications. 
Even as an early career researcher, I recognize the power I own over my students, colleagues, research participants, and myself. However, this power has been very much unexamined and is only appreciated after having read the literature on ethics and being reflexive of my own experiences within tourism research. My own critical reflexivity now reframes power distances between myself and the people I work with in the tourism community be they my superiors, colleagues, coauthors, students, or research participants. In this respect, it is definitely possible for ethics and excellence to coexist for an early career researcher, but this possibility is dependent upon the support from the tourism research community, which is arguably in turn a subcontext of broader changes to university education and demands on researchers.

\section{What Responsibilities do Tourism Researchers Have?}

The responsibilities of any researcher revolve around teaching, research, and service, but having undertaken scholarship in Malaysia, New Zealand, the US, Australia, and working for different institutions around the world as reviewer and examiner, I have learned that while the expectations for teaching and research are usually clear, the guidelines for service are somewhat gray. I understand my responsibilities to the community and attempting to be an ethical academic, I have in the last 42 months delivered 25 seminars or workshops at different universities, and have spoken either as a guest speaker, panelist, or mentor at eight various tourism conferences. I have chaired sessions, organized conferences, and reviewed for conferences as well as journals. However, I do not know if the items listed under "Academic Services" in my curriculum vitae have impressed or will impress my recruitment and promotion committees. The motivations for servicing the community are intrinsically driven and could well be what Fennel (2013) described as ethical. I would like to think that my service to the community has probably been helpful in my internal career, that is, within an organization but whether or not another organization will see this work as important would be an interesting question to ask. Another good question related to interorganization mobility is if external or internal services receive more weighting.
Academic journals remind us of our responsibility as researchers to add and disseminate new knowledge to the academic community, and require that our contribution to theory is articulated. However, another responsibility is to make our work usable for the professional field. For example, to compare the results of research in applied sciences is often reinterpreted in layman terms and/or transformed for practical use, benefitting the industry and society at large, notwithstanding of course, cases of poor ethics and private profit. From an ethical point of view, I have always felt that I need to make my work accessible to those who do not necessarily share the academics' frame of reference. It is important that tourism researchers think about the degree to which our ideas and information actually address real-world environments, concerns of industry practitioners, and issues communities face. To this end, it has been suggested that researchers involve potential stakeholders at different stages of a study, from pre-data collection to post-write up (Maile \& Griffiths, 2014). Given that communities and practitioners are generally unfamiliar with research-based journals (Gopinath \& Hoffman, 1995), suggestions have been made for researchers to become active in organizations and associations where both researchers and practitioners belong (Yin \& Moore, 1988). Yin and Moore even went as far to say that researchers should plan on delivering a product directed for user groups rather than only at research groups. In reviewing multidisciplinary work on knowledge production and dissemination for this reflexive exercise, I am now more convinced that researcher engagement with community is not only a civic responsibility but a form of scholarship (Ward \& Carrigan, 2011). However, until the tourism research community and institutional structures around the world value alternative forms of scholarship other than publications, writing for journals will still be my priorityfor I am, after all, an early career researcher.

Relatedly, access to journals is not one to be taken for granted, and we need to think about how our contribution to knowledge reaches academics in less privileged geographical circumstances. Shortly after beginning my position in Malaysia, I began to realize that many universities in Asia do not have immediate access to library databases. Therefore, access to articles is solely dependent on 
the generosity of authors and kindness of colleagues in research universities who might e-mail through softcopies upon requests. So, our responsibility does not stop at publishing but by thinking about how we can help make our work and ideas reach "less fortunate" colleagues. This includes thinking about where we hold conferences, how much conferences need to cost, barriers to conference attendance, our carbon footprints, and what we can do for institutions around the conference venue. Ethical questions around conference attendance by tourism researchers should be discussed (Hall, 2010).

In a university setting that is normalized as masculine, tourism scholars have the responsibility to be more inclusive of those who do not fit into the "old, white, male" profile. Much research has shown that the patriarchal ideologies of academia alienate faculty members who are young, female, and of other races (see for example, Berry \& Mizelle, 2006; Currie, Thiele, \& Harris, 2002; Hune, 1997; Lee, 2002; Li \& Beckett, 2006; Liinason, 2012; Mayuzumi, 2005; Mercer, 2013; Wroblewski, 2012). The underrepresentation of minorities on leadership, management committees, editorial boards, and pools of keynote speakers deprives them of the occasion to contribute towards research on an equal footing. The lack of different perspectives from the diversity minority can bring could mean that the quality of research suffers. Therefore, current meritocracy discourse that replicates exclusions and privileges should be deconstructed and reconstructed. As a member of the minority group, I can understand the diverse challenges for attaining academic success and realize that there is still much more to do to address the gender gap within the tourism academy (Munar et al., 2015).

\section{Conclusion}

This work is probably the most uncomfortable I have undertaken. Confessing to my own inadequacies is difficult yet my reflexive analysis has catalyzed what I believe would be important shifts in my career. Having undergone this reflexive engagement with critical issues such as identity, power, and responsibility in academia, I acknowledge that it is most challenging for an early career researcher not to play "the neoliberal game to ensure the viability of our schools and our own ongoing job security” (Klocker \& Drozdzewski, 2012, p. 2). However, I am also optimistic that future early career researchers can indeed succeed in the current tourism academic environment without having to compromise on ethics. To do so, I highly recommend that academics in general, but early career researchers in particular, commit to a reflexive exercise that incorporates the three main questions asked in this article, at least on an annual basis. To this end, academic promotion committees could consider adding a section to current application documents that requires candidates to address these questions on the ethics of excellence, in addition to their achievements in teaching, research, and service. Therefore, research productivity measurement should take into account alternative forms of excellence and allows for diverse research subjectivities to excel. Institutional structures and the tourism research community should also highlight the importance of codes of conduct among their new cohorts of researchers. This education on the ethics of excellence can be easily introduced into existing doctoral students and academic staff orientation programs. These strategies will ensure that important dialogues on the morals of excellence and discussions on the ethical measurement of success occur throughout an academic's career.

This article contributes to the tourism academy in three ways. First, it addresses the call for academics to be critically reflexive (Finlay, 2002; Hall, 2004). Second, it ponders on the role of ethics of tourism researchers in their quest to excellence, which has only been recently discussed (Fennell, 2013; Moscardo, 2010). It does so by drawing on my personal experiences and contributes to the increasing attention placed on the welfare of early career researchers (see, e.g., Bazeley, 2003; Bazeley et al., 1996; Foote, 2010; Johnson, 2011; Laudel \& Gläser, 2008; Mercer, 2013; Orlando \& Gard, 2014) and minority groups of faculty members (Berry \& Mizelle, 2006; Currie et al., 2002; Hune, 1997; Lee, 2002; Li \& Beckett, 2006; Mayuzumi, 2005, 2008). Finally, although written from the perspective of an early career researcher, this article is to an extent a reminder to the general tourism research community of the responsibilities that accompany the power associated to our title and knowledge. This section of the article is less a conclusion and more a call for all tourism researchers to engage 
reflexively with the ethics of excellence. I hope that as more of us do so, tourism researchers will "have more to offer" (Fennell, 2013, p. 421) and tourism as a field of study will not again be ranked the "worst performing sector" (Hall, 2011b). I will certainly attempt to do so, while keeping my eye on the criteria for promotion.

\section{References}

Ballinger, C., \& Payne, S. (2000). Falling from grace or into expert hands? Alternative accounts about falling in older people. The British Journal of Occupational Therapy, 63(12), 573-579.

Bazeley, P. (2003). Defining "early career" in research. Higher Education, 45(3), 257-279.

Bazeley, P., Kemp, L., Stevens, K., Asmar, C., Grbich, C., Marsh, H., \& Bhathal, R. (1996). Waiting in the wings: A study of early career academic researchers in Australia. Canberra, Australia: Australian Government Publishing Service.

Becher, T., \& Trowler, P. R. (2001). Academic tribes and territories: Intellectual enquiry and the culture of disciplines (2nd ed.). Buckingham, UK: The Society for Research into Higher Education \& Open Univeristy Press.

Berry, T. R., \& Mizelle, N. D. (2006). From oppression to grace: Women of color and their dilemmas in the academy. Sterling, VA: Stylus.

Botterill, D., \& Platenkamp, V. (2012). Key concepts in tourism research. London, UK: Sage.

Brewer, J., \& Hunter, A. (2006). Foundations of multimethod research: Synthesizing styles. Thousand Oaks, CA: SAGE.

Bulmer, M. (1982). Social research ethics: An examination of the merits of covert participant observation. Boulder, CO: Lynne Rienner Publishers.

Carson, L., Bartneck, C., \& Voges, K. (2013). Overcompetitiveness in academia: A literature review. Disruptive Science and Technology, 1(4), 183-190.

Chubin, D. E., \& Connolly, T. (1982). Research trails and science policies: Local and extra-local negotiation of scientific work. In N. Elias, H. Martins, \& R. Whitley (Eds.), Scientific establishments and hierarchies (pp. 293-311). Dordrecht, Netherlands: Reidel.

Currie, J., Thiele, B., \& Harris, P. (2002). Gendered universities in globalized economies: Power, careers, and sacrifices. Lanham, MD: Lexington Books.

Darbi, W. P. K., \& Hall, C. M. (2014). Elite interviews: Critical practice and tourism. Current Issues in Tourism, 17(9), 832-848.

Donyadide, A. (2010). Ethics in tourism. European Journal of Social Sciences, 17(3), 426-433.

Dunkley, R. A. (2007). Re-peopling tourism: A "hot approach" to studying thanatourist experiences. In I. Alteljevic, A. Pritchard, \& N. Morgan (Eds.), The critical turn in tourism studies: Innovative research methodologies (pp. 371-385). Oxford, UK: Elsevier.
Easterby-Smith, M. T., \& Thorpe, R. L. (1991). Management research: An introduction. London, UK: SAGE Publications Inc.

Ellis, C. (2004). The ethnographic I: A methodological novel about autoethnography. Walnut Creek, CA: Alta Mira Press.

Faden, R. R., Beauchamp, T. L., \& King, N. M. (1986). A history and theory of informed consent. New York, NY: Oxford University Press.

Fennell, D. (2013). The ethics of excellence in tourism research. Journal of Travel Research, 52(4), 417-425.

Fennell, D. A., \& Malloy, D. C. (1999). Measuring the ethical nature of tourism operators. Annals of Tourism Research, 26(4), 928-943.

Fennell, D.A., \& Malloy, D. C. (2007). Codes of ethics in tourism: Practice, theory, synthesis. Clevedon, UK: Channel View.

Finlay, L. (2002). Negotiating the swamp: The opportunity and challenge of reflexivity in research practice. Qualitative Research, 2(2), 209-230.

Finn, M., Elliott-White, M., \& Walton, M. (2000). Tourism and leisure research methods: Data collection, analysis, and interpretation. Harlow, UK: Pearson Education.

Foote, K. E. (2010). Creating a community of support for graduate students and early career academics. Journal of Geography in Higher Education, 34(1), 7-19.

Fowler, F. J. (2014). Survey research methods (5th ed.). Thousand Oaks, CA: SAGE.

Gopinath, C., \& Hoffman, R. C. (1995). The relevance of strategy research: Practitioner and academic viewpoints. Journal of Management Studies, 32(5), 575-594.

Grbich, C. (1998). The academic researcher: Socialisation in settings previously dominated by teaching. Higher Education, 36(1), 67-85.

Hall, C. M. (2004). Reflexivity and tourism research: Situating myself and/with others. In J. Phillimore \& L. Goodson (Eds.), Qualitative research in tourism: Ontologies, epistemologies and methodologies (pp. 137-155). London, UK: Routledge.

Hall, C. M. (2010). Academic capitalism, academic responsibility and tourism academics: Or, the silence of the lambs? Tourism Recreation Research, 35(3), 298-301.

Hall, C. M. (2011a). Fieldwork in tourism/touring fields: Where does tourism end and fieldwork begin. In C. M. Hall (Ed.), Fieldwork in tourism: Methods, issues and reflections (pp. 7-18). Abingdon, UK: Routledge.

Hall, C. M. (2011b). Publish and perish? Bibliometric analysis, journal ranking and the assessment of research quality in tourism. Tourism Management, 32(1), 16-27.

Hillen, M., Scholl, I., Martinelli, V., Gudzune, K., \& Pype, P. (2013, September). "Express rather than impress": Discussing individual research challenges among a group of early career researchers. Paper presented at the International conference on Communication in Healthcare, Montreal, Canada.

Hook, D. D. (1984). First names and titles as solidarity and power semantics in English.International Review of Applied Linguistics in Language Teaching, 22(3), 183-190. 
Hudson, L. A., \& Ozanne, J. L. (1988). Alternative ways of seeking knowledge in consumer research. Journal of Consumer Research, 14(4), 508-521.

Hune, S. (1997). Higher education as gendered space: AsianAmerican women and everyday inequities. Everyday Sexism in the Third Millennium, 181-196.

Jamal, T., Smith, B., \& Watson, E. (2008). Ranking, rating and scoring of tourism journals: Interdisciplinary challenges and innovations. Tourism Management, 29(1), 66-78.

Jamieson, J. (2000). Negotiating danger in fieldwork on crime: A researcher's tale. In G. Lee-Treweek \& S. Linkogle (Eds.), Danger in the field: Risk and ethics in social research (pp. 61-71). London, UK: Routledge.

Jogaratnam, G., Chon, K., McCleary, K., Mena, M., \& Yoo, J. (2005). An analysis of institutional contributors to three major academic tourism journals: 1992-2001. Tourism Management, 26(5), 641-648.

Johnson, A. M. (2011). Charting a course for a successful research career: A guide for early career researchers (2nd ed.). Amsterdam, Netherlands: Elsevier.

Klocker, N., \& Drozdzewski, D. (2012). Survival and subversion in the neoliberal university. Responses to the Symposium on the Participatory Geographies Research Group’s “Communifesto for Fuller Geographies: Towards Mutual Security.” Retrieved from https://radicalantipode. files.wordpress.com/2012/10/klocker-and-drozdzewskiresponse.pdf

Laudel, G., \& Gläser, J. (2008). From apprentice to colleague: The metamorphosis of early career researchers. Higher Education, 55(3), 387-406.

Law, R., \& Chon, K. (2007). Evaluating research performance in tourism and hospitality: The perspective of university program heads. Tourism Management, 28(5), 1203-1211.

Lee-Treweek, G., \& Linkogle, S. (Eds.). (2000). Danger in the field: Risk and ethics in social research. London, UK: Routledge.

Lee, S. M. (2002). Do Asian American faculty face a glass ceiling in higher education? American Educational Research Journal, 39(3), 695-724.

Li, G., \& Beckett, G. H. (2006). "Strangers" of the academy: Asian women scholars in higher education. Sterling, VA: Stylus.

Liamputtong, P. (2006). Researching the vulnerable: A guide to sensitive research methods. Thousand Oaks, CA: Sage.

Liinason, M. (2012). Successes and its paradoxical effects: Gender research and processes of institutionalisation. GEXcel Work in Progress Report Volume X, 11, 123.

Macbeth, J. (2005). Towards an ethics platform for tourism. Annals of Tourism Research, 32(4), 962-984.

Maile, S., \& Griffiths, D. (2014). Public engagement and social science. Bristol, UK: Policy Press.

Malloy, D. C., \& Fennell, D. A. (1998). Codes of ethics and tourism: An exploratory content analysis. Tourism Management, 19(5), 453-461.

Mayuzumi, K. (2005). Breaking the silence: Immigrant women faculty, Canadian academy, and the nation-state. Montreal, Canada: American Education Research Association.
Mayuzumi, K. (2008). "In-between”Asia and the West: Asian women faculty in the transnational context. Race Ethnicity and Education, 11(2), 167-182.

McKercher, B. (2005). A case for ranking tourism journals. Tourism Management, 26(5), 649-651.

McKercher, B. (2008). A citation analysis of tourism scholars. Tourism Management, 29(6), 1226-1232.

McKercher, B., Law, R., \& Lam, T. (2006). Rating tourism and hospitality journals. Tourism Management, 27(6), 1235-1252.

Melrose, M. (2002). Labour pains: Some considerations on the difficulties of researching juvenile prostitution. International Journal of Social Research Methodology, 5(4), 333-351.

Mercer, J. (2013). Responses to rejection: The experiences of six women early career researchers in the education department of an English university. Women's Studies International Forum, 38, 125-134.

Meyer, L. H. (2012). Negotiating academic values, professorial responsibilities and expectations for accountability in today's university. Higher Education Quarterly, 66(2), 207-217.

Miller, A. N., Taylor, S. G., \& Bedeian, A. G. (2011). Publish or perish: Academic life as management faculty live it. Career Development International, 16(5), 422-445.

Moscardo, G. (2010). Tourism research ethics: Current considerations and future options. In D. G. Pearce \& R. W. Butler (Eds.), Tourism research: A 2020 vision (pp. 203-214). Oxford, UK: Goodfellow.

Munar, A. M., Biran, A., Budeanu, A., Caton, K., Chambers, D., Dredge, D., . . . Ram, Y. (2015). The gender gap in the tourism academy: Statistics and indicators of gender equality. Retrieved from https://drive.google.com/ file/d/0B3FCyz6drX2Wc3hsS2JzRTJCUGs/view

Mura, P. (2013). “To participate or not to participate?” A reflective account. Current Issues in Tourism, 18(1), 83-98.

National Research Council. (2005). Bridges to independence: Fostering the independence of new investigators in biomedical research. Washington, DC: National Academies Press.

Noy, C. (2008). The poetics of tourist experience: An autoethnography of a family trip to Eilat. Journal of Tourism and Cultural Change, 5(3), 141-157.

Ong, F., Pearlman, M., Lockstone-Binney, L., \& King, B. (2013). Virtuous volunteer tourism: Towards a uniform code of conduct. Annals of Leisure Research, 16(1), 72-86.

Orlando, J., \& Gard, M. (2014). Playing and (not?) understanding the game: ECRs and university support. International Journal for Researcher Development, 5(1), 2-15.

Page, S. J. (2003). Evaluating research performance in tourism: The UK experience. Tourism Management, 24(6), 607-622.

Payne, D., \& Dimanche, F. (1996). Towards a code of conduct for the tourism industry: An ethics model. Journal of Business Ethics, 15(9), 997-1007. 
Pechlaner, H., Zehrer, A., Matzler, K., \& Abfalter, D. (2004). A ranking of international tourism and hospitality journals. Journal of Travel Research, 42(4), 328-332.

Perry, C., Riege, A., \& Brown, L. (1999). Realism's role among scientific paradigms in marketing research. Irish Marketing Review, 12(2), 16-23.

Persson, R. S. (2012). Cultural variation and dominance in a globalised knowledge-economy: Towards a culturesensitive research paradigm in the science of giftedness. Gifted and Talented International, 27(1), 15-48.

Petersen, A. M., Stanley, H. E., \& Succi, S. (2011). Statistical regularities in the rank-citation profile of scientists. Scientific Reports, 1(181).

Petersen, E. B. (2006, December). Australian early career researchers negotiating the "culture change" of higher education reform. Paper presented at the Australian Sociology Association Annual Conference, Perth, Australia.

Ryan, C. (2005). The ranking and rating of academics and journals in tourism research. Tourism Management, 26(5), 657-662.

Schäfer, R. B., Cooke, S. J., Arlinghaus, R., Bonada, N., Brischoux, F., Casper, A. F., . . . Rolland, V. (2011). Perspectives from early career researchers on the publication process in ecology-A response to Statzner \& Resh (2010). Freshwater Biology, 56(11), 2405-2412.

Tilghman, S. (1998). Trends in the early careers of life sciences. Washington, DC: National Academies Press.

van Dalen, H. P., \& Henkens, K. (2012). Intended and unintended consequences of a publish-or-perish culture: A worldwide survey. Journal of the American Society for Information Science and Technology, 63(7), 1282-1293.
Veal, A. J. (2006). Research methods for leisure and tourism: A practical guide (3rd ed.). London, UK: Prentice Hall.

Ward, C., \& Carrigan, M. (2011). Are all forms of scholarship considered equal? Contemporary Issues in Education Research, 2(2), 45-50.

Weeden, C., \& Boluk, K. (Eds.). (2014). Managing ethical consumption in tourism. New York, NY: Routledge.

Wenstøp, F., \& Koppang, H. (2009). On operations research and value conflicts. Omega, 37(6), 1109-1120.

Wheeler, M. (1995). Tourism marketing ethics: An introduction. International Marketing Review, 12(4), 38-49.

Wright, S. K. (2009). Forms of address in the college classroom. In W. Ahrens, S. Embleton, \& A. Lapierre (Eds.), Names in multi-lingual, multi-cultural, and multi-ethnic contact: Proceedings of the 23rd International Congress of Onomastic Sciences (pp. 1079-1087). Toronto, ON: York University.

Wroblewski, A. (2012). Gendered practices in appointment procedures: Familiar and new barriers to women on the path to a professorship. In S. Strid, L. Husu, \& L. Gunnarsson (Eds.), Gender paradoxes in changing academic and scientific organisation(s): Proceedings of the GEXcel theme 11-12 (Vol. X, pp. 65-72). Örebro, Sweden: Centre of Gendering Excellence.

Yin, R. K., \& Moore, G. B. (1988). Lessons on the utilization of research from nine case experiences in the natural hazards field. Knowledge in Society, 1(3), 25-44.

Zhang, Q. (2011). An exploration of the identities of Asian graduate student mothers in the United States. Doctoral dissertation, Indiana University of Pennsylvania, Indiana, PA. Retrieved from https://knowledge.library.iup. edu/etd/689/ 